\title{
Size Effects of Recovered Ti-6Al-4V Alloy Scrap by Conventional P/M Techniques
}

\author{
Mustafa Ustundag, Mehmet Fahri Sarac and Remzi Varol \\ Department of Mechanical Engineering, Suleyman Demirel University, Isparta, 32260, Turkey
}

\begin{abstract}
The main challenges for Titanium alloys are low utilization rate and relatively low recycling ratio. For recycled Ti-6Al-4V alloy industry scrap, sieve analysis and compacting pressures are important parameters that determine its mechanical properties for low-cost Ti-based alloy applications. Titanium alloy scraps milled at various machining speeds ranging from $800 \mathrm{rpm}$ to $1,100 \mathrm{rpm}$ at constant time. Afterwards, sieve analysis classifies powder distribution for four categories such as -40, 40-105, 105-150, 150-212 $\mu \mathrm{m}$. Different particle size distribution range of Ti-6Al-4V alloy industry scrap is compacted at various pressure (from $600 \mathrm{MPa}$ to 1,500 $\mathrm{MPa}$ ) and then sintered for final product. Three-point bending and microstructural evaluation were conducted on both commercially available and recycled Ti-6Al-4V alloy industry scrap to evaluate which particle size distribution gives better mechanical performance, uniform distribution and high apparent density. Results indicate that scrap particle, which has less than $-40 \mu \mathrm{m}$ size distribution, compacted at 1,050 MPa and sintered at $1,200{ }^{\circ} \mathrm{C}$ under high vacuum $\left(10^{-6} \mathrm{mbar}\right)$ gives $99.5 \%$ apparent density while green density of Ti-6Al-4V alloy industry scrap was about to $80 \%$.
\end{abstract}

Key words: Ti-6Al-4V, scrap, size effect, compaction, sintering.

\section{Introduction}

Titanium (Ti), reactive metal, are known as expensive materials to produce due to its limitation in refining process. Titanium can be alloyed with many elements and resulted on high strength-to-weight ratio, toughness, low thermal expansion, good processability, excellent corrosion resistance and improving its biocompatible properties [1]. Ti-6Al-4V is a Ti alloy type which is produced to increase the mechanical properties of $\mathrm{Ti}$ and is the most commonly used $\mathrm{Ti}$ alloy in the biomedical industry as an implant material. Therefore, $\mathrm{Ti}$ demand is drastically increasing depending on the progress of technology and the fields of application are considerably higher regardless of the high expenses of Ti alloy product.

However, due to the rapid increase in demand for titanium implants in the world and the high cost of titanium alloys, the need for recycled and cheap raw materials has come to forefront. For this reason,

Corresponding author: Mustafa Ustundag, Ph.D., research assistant, research fields: powder metallurgy, sintering, hot isostatic pressing, titanium. efficient recycling technologies and methods of using recycled titanium raw materials are rapidly gaining importance. Particularly during the machining operations, low utilization rate and high amounts of energy are consumed during the recycling of these raw materials by conventional methods. In this case, the necessity of using more efficient methods such as cold heart melting (CHM) and vacuum arc re-melting (VAR) for the recycling of these chips is on the foreground. But those methods are expensive and give inhomogeneous composition at the end product [2].

The effect of recycling $\mathrm{Ti}$ alloy powder on mechanical properties of bulk parts is not clear. Some studies described that certain powders could be recycled many times without affecting their mechanical properties of its end product [3-11]. Tang et al. [12] found that 21-time recycle of $\mathrm{Ti}$ alloy powder shows higher ultimate tensile and yields strength. Because of number of recycled increase, powders exposed to air and powder particle size distribution become narrower up to $80 \mu \mathrm{m}$. During clean-up process, reduced moisture in the recycled 
powder at high temperature $\left(>550{ }^{\circ} \mathrm{C}\right)$ enables to minimize residual stresses. However they did not find a significant change in powder morphology or particle size distribution for recycled powder products and also no research described on mechanical properties of specific particle size distributed recycled Ti alloy parts.

In this study, Ti-6Al-4V metal powder was produced by mechanical grinding methods using used Ti-6Al-4V implant chips. To compare their mechanical properties and microstructural evaluation, the recycled and classified powder distribution of Ti-6Al-4V powders and commercially available Ti-6Al-4V metal powders were prepared by conventional $\mathrm{P} / \mathrm{M}$ techniques and sintered for final product. At various pressure, powder compaction was tested to find highest apparent density. Mechanical properties of the two groups were evaluated using three-point bending. Recycled powder properties, such as particle size distribution, chemical composition and microstructure are evaluated and compared against that of the commercially available Ti-6Al-4V powder.

\section{Experimental Setup}

The Ti scrap used in this study was residual machining chips of Ti-6Al-4V bars. The process of recycling Ti alloy scrap began with cleaning, raw scrap, milling and sieving process respectively. Milling was operated by Retsch Vibratory Disc Mill RS 200 and sieving was analyzed on Retsch Vibratory Sieve Shaker AS 200. After milling the raw scrap at $700 \mathrm{rpm}$ for $1 \mathrm{~min}$, raw scrap was crushed to obtain fine chips suitable for milling pod. Afterwards, for getting finest powder distribution, powders were re-milled at 800, 900 and 1,000 rpm for $10 \mathrm{~min}$. Each milling condition was collected and sieved as -100 , 100-200, $+200 \mu \mathrm{m}$ size range.

Particle size distribution of classified raw powders and commercially available Ti-6Al-4V powders were performed with Malvern Masterseizer 2000 particle size analyzer for confirming their sieve analysis. After particle size analysis, all powders were re-sieved to classify as following -40, 40-105, 105-150, 150-212 $\mu \mathrm{m}$ particle size range.

Before compaction test, for each particle size distribution at above, green density was calculated according to Hall-Petch relation. Compaction test was performed at various pressure ranging from 600 to 1,500 MPa. Sintering took place in ALD high vacuum sintering furnace. Sintering parameters for all samples were fixed at $1,200{ }^{\circ} \mathrm{C}$ for 2 hours under $10^{-6} \mathrm{mbar}$ vacuum pressure. Mechanical tests were conducted for evaluating the as-sintered scrap powders and commercially available Ti-6Al-4V alloy. The microstructure was observed by Olympus-B51 optical microscope. Particle shape and elemental analysis were characterized by Quanta FEG 250 scanning electron microscopy (SEM). A computer controlled Shimadzu/AG-IC instrument is used to evaluate flexural strength by three-point bending test.

\section{Experimental Results}

\subsection{Analysis of Powder Properties}

\subsubsection{Powder Morphology}

Fig. 1a shows the SEM images of $-40 \mu \mathrm{m}$ sized sieved raw powders and commercially available Ti-6Al-4V powder distribution before compaction. It is seen that the dust grains are in irregular, angular and inhomogeneous shapes due to HDH grinding method applied on metal powders. Another reason for the irregular shape and size distribution observed in the commercially available metal powders is accumulation. Depending on the milling time and temperatures, grains were agglomerated or mechanically clamping by secondary binding forces.

Same as Fig. 1a, Fig. 1b shows similar agglomeration and forging effect on commercially available Ti-6Al-4V metal powders. Main differences between the two metal powders are that, $-40 \mu \mathrm{m}$ sized sieved raw powders have much more rounded corners since the frictional effect that both the powder particles in the pulverized disk grinder are in contact with each other and the powder particles are rubbed 
against the pot walls and discs in the vibratory disc mill.

\subsubsection{Apparent Density and Flow Rate}

Fluency and apparent density strongly depends on the powder characteristics such as powder particle size, shape, homogeneity, surface topography and powder size distribution. Flow rate relies on total surface area between powder particles. The increase in surface area and decrease in dust particles, the decrease the fluidity as it increases the friction surface area. In order to determine the effects of recycling on the various powder properties, as shown in Fig. 2, particle size distribution, apparent density and flowability value are measured and classified on both recycled and commercially available Ti-6Al-4V powders.

Apparent density decreased with getting smaller the powder size range. However their apparent density at
$-40 \mu \mathrm{m}$ particle size shows no flow rate because of higher surface area in contact with each powder. The high surface area results in increased friction between the powder granules and a heavier accumulation of large sized powders.

Due to their rounded corners and homogeneous morphological structure on recycled powders, it is clearly seen that recycled powder shows higher flowability and lower apparent density than commercially available powders regardless of their particle size distribution.

\subsection{Analysis of Manufactured Specimen Properties}

\subsubsection{Pre- \& Post-sintered Density}

According to the literature survey, it has been determined that the $85 \%$ theoretical density is an ideal
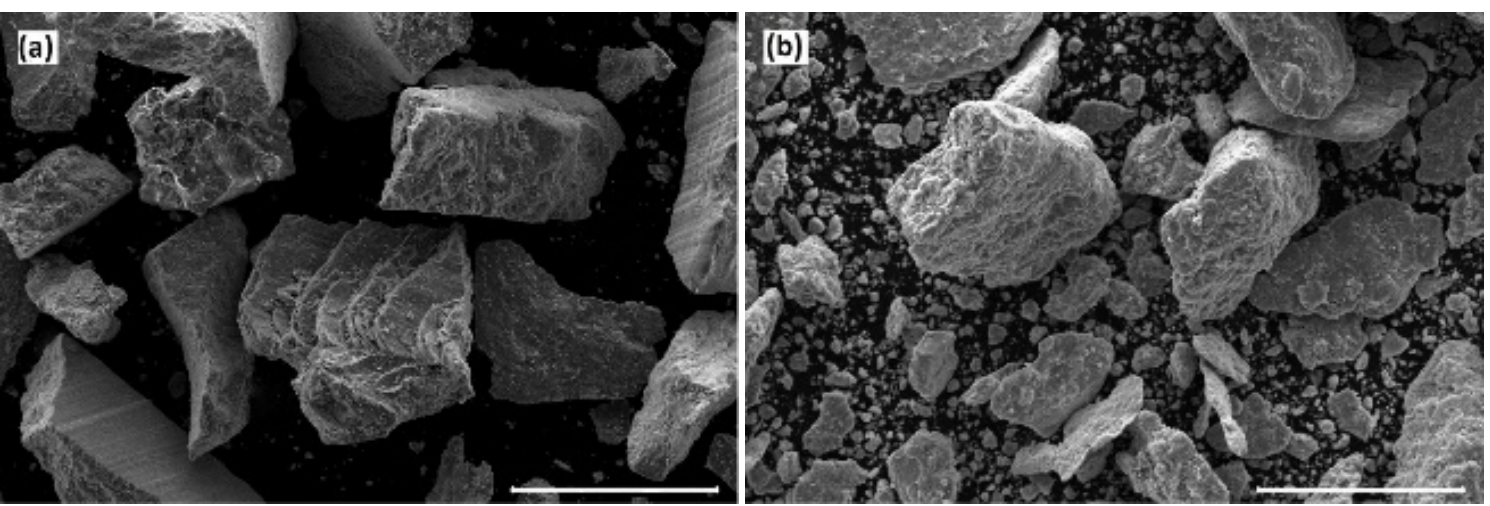

Fig. 1 SEM images of (a) commercially available $-40 \mu \mathrm{m}$ sized sieved Ti-6Al-4V powder, (b) recycled $-40 \mu \mathrm{m}$ sized sieved powders before compaction.

The SEM scale bar for samples set as $100 \mu \mathrm{m}$.

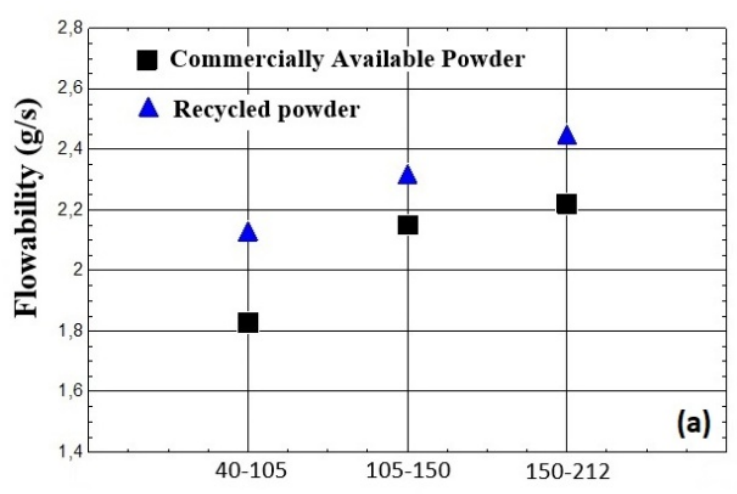

Particle Size Distribution $(\mu \mathrm{m})$

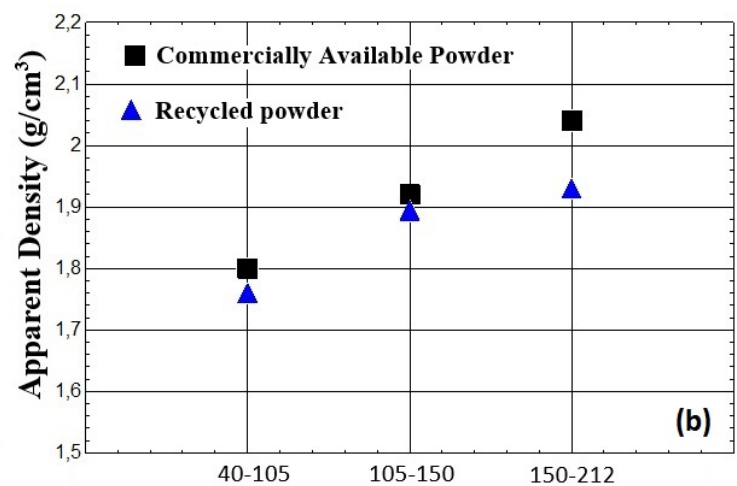

Particle Size Distribution $(\mu \mathrm{m})$

Fig. 2 Comparison of commercially available and recycled powders in terms of particle size distribution against (a) flowability, (b) apparent density. 
pre-sintering density value [6]. In order to get $85 \%$ theoretical density, pre-sintered density measurements were made at different pressure. For $-40 \mathrm{~m}$ raw powder, zinc stearate was used as lubricant for easily removing from the mold. By starting from $600 \mathrm{MPa}$ to 1,500 MPa pressure, $85 \%$ pre-sintering density value reached at 1,150 MPa and its relative density is 3.66 $\mathrm{g} / \mathrm{cm}^{3}$. Experimental studies have shown that even though higher relative density values are reached at pressures higher than $1,150 \mathrm{MPa}$, these pressure values damage the mold and do not significantly increase the relative density value. All samples to be used in the compression tests were made with reference to the pressure value of 1,150 MPa.

After compacting all samples at 1,150 $\mathrm{MPa}$, all samples were being sintered together at $1,200{ }^{\circ} \mathrm{C}$ for 2 hours under $10^{-6}$ mbar vacuum pressure. One percent mass loss of Zinc stearate was observed in each sample due to evaporation during sintering. Sintered samples reached 99\%-99.5\% relative density.

\subsubsection{Three-Point Bending Test}

Flexural strengths of fractured samples were measured by three-point bending test. As shown in Fig. 3, samples of recycled Ti-6Al-4V have $468.58 \mathrm{MPa}$ average flexural strength while commercially available Ti-6Al-4V has $665.83 \mathrm{MPa}$. Depending on their particle shape, the more angular and irregular structure of powder is in contact with each other; resulting in increased contact surface quantities and, consequently, increased diffusion field during sintering.

Apart from their flexural strength, elongation modulus of recycled powder shows higher value than commercial one since neck formation against recycled powders change form and become more elongated. This could be a consequence of additional particle movement during the sintering process.

\subsubsection{Microstructure}

Fractured samples were investigated by scanning electron microscopy (SEM). By investigating both fractured commercially available and recycled Ti-6Al-4V samples, it appears that the type of fracture on the macroscale is brittle and there is a proportionally higher break in grain in commercially available samples (Fig. 4a). It can be said that the neck mechanisms that increase the strength are acting as the beginning of breaking in the grain and that this situation reduces the ductility. It can also be seen that

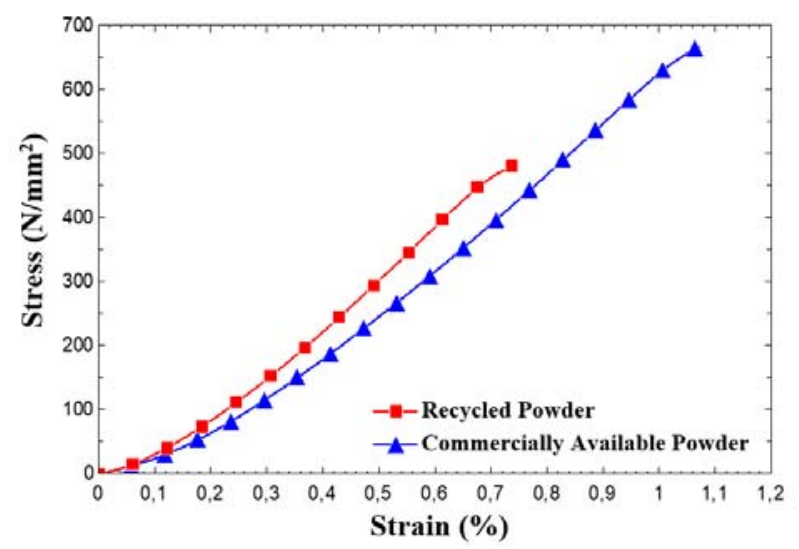

Fig. 3 Flexural strength of $-40 \mu \mathrm{m}$ sieved recycled and commercially available $\mathrm{Ti}-6 \mathrm{Al}-4 \mathrm{~V}$ powders.
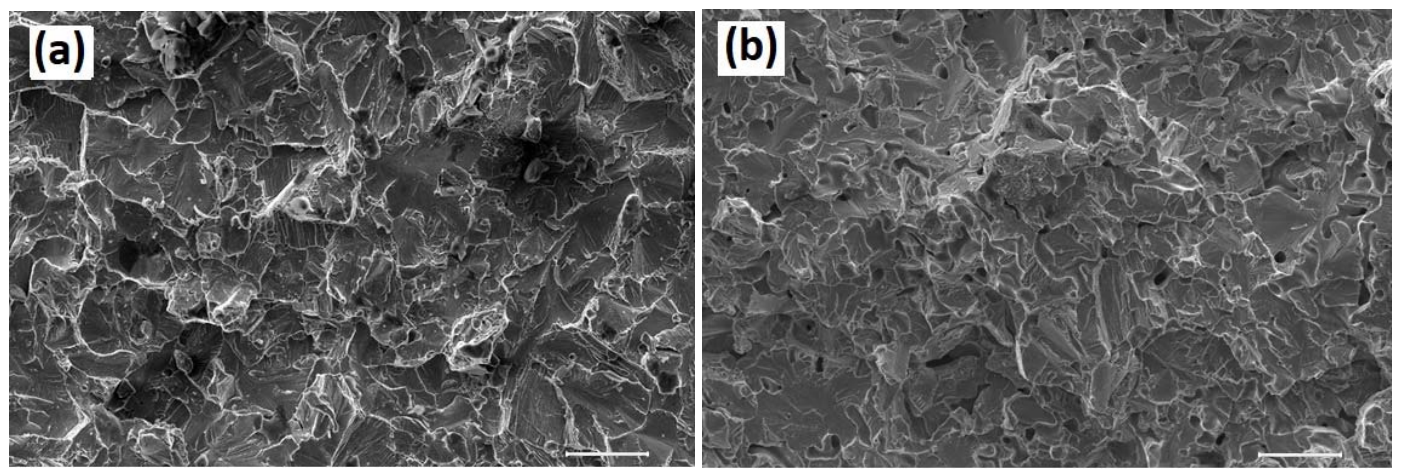

Fig. 4 Fractured surfaces of all samples sintered at $1,200{ }^{\circ} \mathrm{C}$ for 120 minutes: (a) commercially available and (b) recycled samples.

The SEM scale bar for all samples set as $100 \mu \mathrm{m}$. 

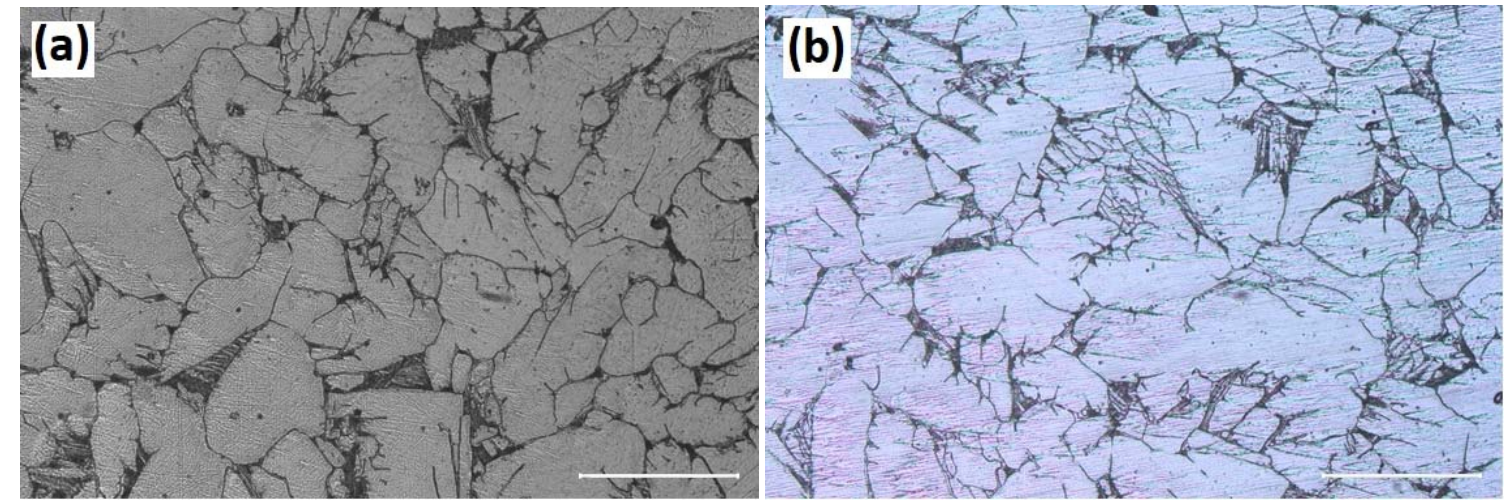

Fig. 5 Optical microscope image of (a) commercially available and (b) recycled Ti-6Al-4V alloys.

The optical microscope scale bar is set as $100 \mu \mathrm{m}$.

the porosity is not formed in the samples produced from recycled alloys (Fig. 4b).

As seen in Fig. 5, investigation of pore size distribution, distribution of $\alpha / \beta$ phases, grain boundary and grain irregularity were investigated by optical microscope for all samples. $\alpha$ (hexagonal close packed-HCP) phases are shown in region A (bright surface) and $\beta$ phases are seen in regions indicated by $\mathrm{B}$ (dark surface). The $\beta$ (BCC) phase has a much more ductile structure than $\alpha$ phase. The $\beta$ phase conversion is low due to the fact that the cooling rate is kept at very low levels during the sintering process. The high rate of $\alpha$ phase in the microstructure confirms that the samples behave brittle.

\section{Conclusions}

The following conclusions can be made from this study.

- The powder morphology of the recycled Ti-6Al-4V powder is more rounded than commercially available powder Ti-6Al-4V powder due to powders behavior during milling process.

- Powder flowability and apparent density are significantly affected by particle size, shape and particle size distribution.

- Increase in fine powder size or an increase in spherical powder would contribute to the improved powder flow, increased apparent density and particle size distribution.

- Small change in mechanical properties of recycled and commercially available Ti-6Al-4V alloys were observed.

- Driving force that affects the material microstructure and phase distribution is the temperature conditions and durations during sintering process.

\section{Acknowledgments}

This research was supported by Faculty Member Training Program funded by Council of Higher Education [OYP-05276-DR-12]. The authors would like to thank Dr. Erdem Camurlu on specimen preparation of SEM and Optical Microscopy analysis and Department of Mechanical Engineering, Katip Celebi University for their help in recycled powder production supply. The authors also give special thanks to KLP Cutting Tools Company for their assist and guidance on sintering processes for all samples.

\section{References}

[1] Guitar, A., Vigna, G., and Luppo, M. I. 2009. "Microstructure and Tensile Properties after Thermo Hydrogen Processing of Ti-6Al-4V." Journal of Mechanical Behavior of Biomedical Materials 2 (2): 156-63.

[2] Oh, J. M., Roh, K. M., Lee, B. K., Suh, C. Y., Kim, W., Kwon, H., and Lim, J. W. 2014. "Preparation of Low Oxygen Content Alloy Powder from Ti Binary Alloy Scrap by Hydrogenation-Dehydrogenation and Deoxidation Process." Journal of Alloys and Compounds 593: 61-6.

[3] Hill, S. 2001. "Titanium Revolution." New Scientist Magazine 170: 2297. 
[4] Lütjering, G., and Williams, C. 2003. Titanium. Heidelberg: Springer-Verlag.

[5] Lütjering, G., and Williams, C. 2007. Engineering Materials and Processes. Springer.

[6] German, R. M. 1989. "Powder Metallurgy Science." In Metal Powder Industries Federation, USA, 203-335.

[7] Frykholm, R., and Brash, B. 2016. "Press and Sintering of Titanium." Key Engineering Materials 704.

[8] Lin, W. C., Ju, P. C., and Chern Lin, J. H. 2005. "A Comparision of the Fatigue Behaviour of the Cast $\mathrm{Ti}$ 7.5Mo with Cp Titanium, Ti-6Al-4V and Ti-13Nb-13Zr Alloys." Biomaterials 26: 2899-907.

[9] Yan, Y., Nash, G. L., and Nash, P. 2013. "Effect of Density and Pore Morphology on Fatigue Properties of Sintered Ti-6Al-4V." International Journal of Fatigue 55: 81-91.
[10] Cao, F., Chandran, R., and Kumar, P. 2017. "New Approach to Achieve High Strength Powder Metallurgy Ti-6Al-4V Alloy through Accelerated Sintering at $\beta$-Transus Temperature and Hydrogenation-Dehydrogenation Treatment." Scripta Materialia 130: 22-6.

[11] Silva, A. A. M., Santos, J. F., and Strohaecker, T. R. 2005. "Microstructural and Mechanical Characterisation of a Ti-6Al-4V/TiC/10p Composite Processed by the BE-CHIP Method." Composites Science and Technology 65: 1749-55.

[12] Tang, H. P., Qian, M., Liu, N., Zhang, X. Z., Yang, G. Y., and Wang, J. 2015. "Effect of Powder Reuse Times on Additive Manufacturing of Ti-6Al-4V by Selective Electron Beam Melting." Journal of the Minerals, Metals \& Materials Society 67 (3): 1-12. 